Jewish leaders seek genetic guidelines...

[SAN FRANCISCO] US Jewish leaders are asking officials of the National Human Genome Research Institute (NHGRI) to discuss the possible development of working guidelines for genetic research on Ashkenazi Jews. They are alarmed by the sentiments reflected in recent newspaper headlines, such as one in New York Newsday which referred to bias against "mutant gene carriers".

The current level of research attention by geneticists "feels uncomfortable to the Jewish community", says Amy Rutkin, director of American affairs for Hadassah, the United States' largest Jewish membership organization. "But we understand how important this life-saving research is."

Geneticists at Johns Hopkins University in Baltimore, Maryland, recently reported that they had found a genetic mutation in one of about 17 Ashkenazi Jews - those of Eastern European descent - that seems to double the risk of colon cancer (see Nature Genetics 17, 79-83; 1997). The research group says the mutation may be the most common cancer gene found so far within a particular population.

Their study adds to a growing list of mutations in the Ashkenazi population linked to disease, including Tay Sachs, Gaucher's and the 185delAG mutation associated with breast and ovarian cancer.

Such findings, which have already led to Jewish groups being targeted as a potential market for commercial genetic tests, could create the perception that Jewish people are unusually susceptible to disease, says Rutkin.

As a result, she warns, anyone with a Jewish-sounding last name could face discrimination in insurance and employment as companies struggle to keep down healthcare costs. Hadassah has been lobbying for laws to forbid genetic discrimination. "Social stigmatization is a profound issue for our community," Rutkin says.

History reinforces such fears. The eugenics movement in the 1920 s viewed Eastern and Southern Europeans as genetically inferior in intelligence and prone to criminality. In the United States, these views spurred laws that limited immigration by Jews, other Eastern Europeans and Italians.

For NHGRI, Leslie Fink confirms that discussions are taking place about a formal dialogue with representatives of the Jewish community. She says the institute recognizes that it has a responsibility to combat stigmatization based on genetic difference, and is discussing how to deal with the problem.

Although every individual carries an equal number of genetic mutations that could lead to disease, more is known about the mutations prevalent in certain populations — including Ashkenazi Jews, Finns and
Mormons - partly because researchers have found find these communities relatively convenient to study.

The main reasons are that they are identifiable as a genetically linked population and they tend to keep good genealogical records. As a result, it is much easier to track the presence of a particular mutation, its frequency and its link to the development of disease than it is among undocumented populations.

Another factor is that Jewish people in the United States have long been involved with genetic studies out of both commitment to public service and an awareness of the potential medical benefit to themselves. Genetic screening for Tay Sachs in this community is often held up as an example of the benefits such testing can bring.

But Harry Ostrer, a geneticist at New York University Medical Center who took part in the colon cancer research, says that some religious leaders, concerned about

stigmatization both outside and within the Jewish community, have recently said that they would prefer genetic research on the Ashkenazi population to be abandoned altogether.

Ostrer warns that the premature introduction of genetic tests based on new findings could help to create false impressions and stimulate the discrimination that community activists fear. Hadassah wants to head off any possible backlash against genetic research among Ashkenazi Jews by educating both sides, Rutkin says. She praises NHGRI officials for helping to place recent findings in context.

But Rutkin says it is important for both researchers and members of the community to understand the full implications of genetic research. Scientists must also be more aware, she says, of the ways in which antisemitic notions of the past can become reflected in the interpretation of genetic research today.

SallyLehrman

\title{
as Israel offers to test adopted children
}

[JERUSALEM] Israel's Ministry of Science has offered to fund DNA tests for 1,000 Israelis of Yemenite extraction to resolve a long-standing controversy about the fate of children who may have been adopted without their parents' knowledge or consent.

In the early 1950s, a number of Yemenite parents who had recently immigrated to Israel from Yemen and who were living in poverty in transit camps were told that children of theirs who had been hospitalized had died. Often, the parents were taken to their children's supposed graves. Many suspected, however, that the children had been adopted by wealthier families.

These suspicions are supported by testimony heard by a government commission investigating the affair. Earlier this year, an Israeli-born woman now living in the United States travelled to Israel for a DNA test and claims to have been reunited with her biological parents as a result.

In a proposal to the Knesset's special committee on research and science and development affairs, Adam Friedman, director of the Molecular Biology and Genetic Engineering Unit at Hadassah University Hospital, said that family relationship could be determined by comparing the alleles of several DNA markers in adopted children with those of their supposed biological parents or siblings.

If a given allele is rare among Yemenite Jews, it can provide a strong indication of genetic relationship between two people who carry it, Friedman explained. The greater the number of such rare alleles that are found to be shared by two people, the greater the probability that they are close relatives, he added.

Yemenite Jewish groups now want the government to conduct such tests on all the affected families and on children who were adopted during the early 1950s.

Friedman estimates that such a large-scale test would cost about $\$ 200,000$.

Mordecai Bashari, the director-general of Israel's Ministry of Science, who is a physicist by training and is himself of Yemenite extraction, has described the sum as a "ridiculously small amount" and has offered to find it from his ministry's budget.

But although 435 Yemenite Jewish families have applied to the science committee requesting DNA testing, only 35 of the 830 adopted individuals identified by the investigative commission as connected to the affair have asked to be tested. Dalia Itzik, chair of the committee, points out that there is no legal way to force them to be tested.

The families involved also want the putative graves of their children to be opened and any bones found to be tested.

But Yehuda Hiss, director of the Pathological Institute of the Ministry of Health, says that none of Israel's genetic laboratories has enough experience in extracting and analysing DNA from bones to obtain results that would be acceptable as evidence in court, so they would have to be sent abroad for analysis.

Haim Watzman 